\title{
Electrocochleography in Guinea Pigs
}

\author{
Negin Salehi ${ }^{* 1}$ and Farzaneh Zamiri Abdollahi ${ }^{2}$ \\ ${ }^{1}$ Phd student of audiology, Iran University of Medical Science, Iran \\ ${ }^{2}$ Phd of audiology, Tehran University of Medical Sciences, Iran
}

Submission: April 28, 2018; Published: May 31, 2018

*Corresponding author: Negin Salehi, Phd student of audiology, Iran University of Medical Science, Iran Tel: 009822228051;

Email: Salehi_au@yahoo.com

\begin{abstract}
Electrocochleography is the best electrophysiological measurement for cochlear condition investigation in guinea pig models. In this article, we will review new issues in recording electrocochleography in guinea pigs in two parts including measurement parameters and clinical applications.
\end{abstract}

Keywords: Electrocochleography; Guinea Pig; The cochlea

Abbreviations: EcohG: Electrocochleography; CAP: Compound Action Potential; CM: Cochlear Microphonics; SP: Summating Potential; AP: Action Potential; SGNs: Spiral Ganglion Neurons; FFT: Fast Fourier transformation; DC: Direct Current

\section{Introduction}

Due to tremendous difficulties associated with human experiments on auditory system, such as dissection hardness due to stiff temporal bone, animal models are the best choice for studies on the cochlear physiology. Researchers have shown that range of small mammals like cat, chinchilla, guinea pig, rat, and mouse, are appropriate options for providing insight into the human cochlear physiology. Guinea pigs are one of the classic models in auditory research due to extensive similarities in hearing range and the cochlea's structure with the humans. Many years ago, Georg von Bekesy described the mechanics of cochlea in guinea pigs. On the other hand in 2003, the successful efforts in regenerating the hair cells were done in guinea pigs [1].

One of the best ways of studying the auditory system and specially the cochlea in these animals is recording auditory evoked responses. They represent activity within the auditory system that is stimulated or evoked by sounds. These recordings play a vital role in the identification and diagnosis of auditory system pathologies. Electrocochleography (EcochG) is the earliest auditory evoked response and its components arise from the inner ear and auditory $\left(8^{\text {th }}\right.$ cranial) nerve fibers near the inner ear (distal end of $8^{\text {th }}$ nerve). It is considered as the most advantageous electrophysiological potentials in documentation of cochlear status [2].

Researchers all over the world have investigated the cochlear condition in multiple guinea pig's peripheral auditory system disorders models via EcochG. This article will review the most important measurement parameters as well as clinical applications of EcochG in guinea pigs.

\section{The goals of recording EcochG in Guinea pigs}

One of the main applications of recording EcochG in guinea pigs is better understanding physiology of the auditory system, specially the cochlea. EcochG has several beneficial applications in cochlear physiology studies including studying the role of different channels in mammalian cochlea [3-5], cochlear micromechanics such as nonlinearity [6], possible roles of nitric oxide [7] and effects of changing perilymphatic $\mathrm{K}+$ in the cochlea [8].

Another goal of recording EcochG in guinea pigs is determining the underlying mechanism of cochlear diseases, such as endolymphatic hydrops [9-12], hyperbilirubinemia $[13,14]$, noise-induced hearing loss $[15,16]$, cochlear ischemia [17], perilymphatic fistula [18] and hidden hearing loss [19]. Studying effects of various drugs on cochlear function is the next goal for recording EcochG in guinea pigs. For instance, investigating influence of drug-induced ototoxicity on cochlear function such as cisplatin [20-24], Quinine [25] and ethyl benzene [26], the effect of blood flow promoting drugs [27], the effect of anesthetics such as isoflurane [28], histamine and its antagonists [29], and the effect of a dopaminergic agonist in cochlear physiology and physiopathology [30]. 


\section{Stimulus type}

Three different types of stimuli have been used in articles for recording the EcochG response. Two most dominant stimuli are Clicks and Tone burst. Clicks consisted of biphasic alternating acoustic pulses $(100 \mu \mathrm{s} /$ phase $)[18,28]$ and $100 \mathrm{~ms}$ electrical pulse [17]. Tone bursts included Trains of $8[10,20,21,26,28]$ or $10[9,13,14,29] \mathrm{ms}$ probes, with frequencies of $2-32 \mathrm{KHz}$. The probes had cosine-shaped rise and fall times of $4 \mathrm{~ms}$ at $0.5 \mathrm{kHz}$, $2 \mathrm{~ms}$ at $1 \mathrm{kHz}, 1.5 \mathrm{~ms}$ at $2 \mathrm{kHz}$ and $1 \mathrm{~ms}$ at the higher frequencies $[9,10,13,14,17,18,20,21,26,28,29]$. In one research with the aim of study of CM latency, audiometric tones of 250, 500, 1000, 2000 and $4000 \mathrm{~Hz}$ were used [31].

\section{Electrode locations}

Two main electrode arrays can be used in recording EcochG parameters in guinea pigs. One of them, which is called "round window approach", is the most widespread method for yielding optimal and high quality recordings of the CM, SP, and AP. Animals are anesthetized by an intraperitoneal injection of anesthetics and are placed in a head holder. Body temperature is maintained by a heating pad at $37^{\circ} \mathrm{C}$ [16]. Cochlea is exposed through a dorsal approach [32]. Once the skin and muscles are incised behind the ear, bulla is opened and the round window of the cochlea is exposed [33]. An Ag-Cl-electrode is placed at the round window niche of the ear. Reference and ground electrodes are usually placed on the skull $[34,35]$ or neck musculature [36]. In studies which recording the EcochG response is repeated in multiple time intervals, the electrode is chronically implanted at round window [37].

To measure cochlear responses from either the scala vestibuli or the scala tympani, after using appropriate anesthetic agent, the animal's head is guarded dorsally in stereotactic machinery. The bony frame of bulla is opened and a $0.2 \mathrm{~mm}$ hole is made into the cochlea. The electrode is made of a Teflon coated Ag$\mathrm{Cl}$ recording wire which is placed on scala vestibuli or the scala tympani $[4,9,12,21,38]$.

It is possible also to record the EcochG components by placing the active electrode on posterior superior wall of the external ear canal near the tympanic membrane, and reference and ground electrodes on the vertex and the frontal region respectively [11].

\section{Waveform Analysis}

There are plenty of procedures for analyzing the latency, threshold and amplitude of EcochG components. CAP waveforms are analyzed by determining the amplitude, latency and threshold of the first and second negative peaks (N1 and N2). The CAPs threshold is usually defined as the lowest intensity stimulus which evokes a specific magnitude of CAP $(0.5 \mathrm{mV})[10,26]$. There is also an alternative method which uses a software algorithm and is based on adjusting the level of stimulus until the response is just visually noticeable above the noise floor of the recording [9]. Most researchers use peak to peak amplitude method for analyzing CAP amplitude, as the voltage difference between the first negative peak after stimulus onset (N1) and the following positive peak $[9,10,13]$. While the others believe that as the CAP is principally superimposed on the SP, the amplitude of the CAP (N1) must be measured relative to the SP and not relative to the base line of the recording or the next positive peak $[20,26,28]$.

Using the FFT in a window from stimulus onset to $2 \mathrm{~ms}$ after offset [28], applying a first-order Boltzmann equation to the CM waveform in the second half of the CM waveform [9], or measuring peak-to-peak amplitude in the middle of the sinusoidal response [20] are various techniques of assessing CM amplitude. Measuring the response a few milliseconds after the onset of stimuli is to avoid contamination from CAP [13].

SP can be observed as the DC shift in round window potential occurring both at the onset and offset of the tone and there are arguments for and against using either as the SP measure $[39,40]$. The onset SP could be under-estimated because of the start of the negative-going N1 wave of the CAP, whereas the slower slope of the offset SP is probably the result of contamination by changes in asynchronous neural firing [41]. To overcome these issues, SP amplitude is measured as the difference between the preresponse baseline potential and the $\mathrm{DC}$ level from approximately 5.5-6.5ms following stimulus onset [20], to be concurrent with the relatively stable plateau after the CAP [10].

\section{Clinical Applications}

Endolymphatic Hydrops (EH): Injecting artificial endolymph into scala media in anaesthetized guinea pigs is as an acute model of endolymphatic hydrops [42]. With injecting volumes up to $1-2 \mu \mathrm{l}$ endolymph, results in fundamental changed in EcochG recording parameters. These changes includes an increase in CAP threshold specially at low frequencies [43], an increase in SP amplitude, and also a change in the asymmetric distortion of the $\mathrm{CM}$, resulting from a shift in the nonlinear electro-mechanical transduction [44,45]. Researchers have suggested a mechanism underlying these changes. That is, Reissner's membrane is swelled into scala vestibuli and the organ of Corti is dislocated toward the scala tympani due to increase in hydrostatic pressure of the endolymph [46]. These cases modify cochlear sensitivity and nonlinear mechano-electrical transduction [47]. But when the injected volume increases to $3 \mu \mathrm{l}$, a fast and sudden recovery of the changes is observed, which is highly similar to the clinical findings observed in Meniere's Disease [9]. Receiving dexamethasone can prevent the reported EcochG findings in experimentally-induced endolymphatic hydrops [11].

\section{Hyperbilirubinemia}

Guinea pigs are considered as worthy animals in modeling human cases with hyperbilirubinemia, as their auditory system is immature at birth, and this is a good characteristic in matching these models with preterm neonates with hyperbilirubinemia [13]. To establish the hyperbilirubinemia model, animals 
received an intraperitoneal injection of bilirubin at $100 \mathrm{mg} / \mathrm{kg}$ [48].

The EcochG shows normal CM, elevated CAP threshold, and significantly prolonged peak latencies and duration. These results suggest that hyperbilirubinemia in neonatal guinea pigs impaired auditory peripheral neuromechanisms that targeted mainly the IHC synapses, the myelin sheath of SGNs and their fibers, and there is a potential relationship between hyperbilirubinemia and auditory neuropathy [13]. Receiving taurine, a 2-amino-ethanesulfonic acid, which is an abundant sulfur containing amino acid present in the inner ear in mammals [49], limits bilirubin-induced neural damage in the auditory system, which is revealed by significant attenuation of EcochG abnormalities [14].

\section{Noise Induced Hearing Loss (NIHL)}

Because of high similarities in hearing range between guinea pigs and humans, these small mammals have considered as NIHL model in several researches. The pathogenic mechanisms of noise-induced cochlear damage could be analyzed via EcochG response. The temporary threshold shift as well as permanent threshold shift is reflected in EcochG response as an increase in CAP Threshed and latency [15], and decrease in CM amplitude [16]. The protective effects of antioxidants such as $\mathrm{N}$ acetylcysteine on noise induced hearing impairment, is monitored effectively by investigating the changes in EcochG parameters [15].

Noise exposures that result in reversible changes in cochlear neural threshold can cause a reduced neural output at supra-threshold acoustic stimuli. This so-called "hidden hearing loss" [50], is associated with a selective loss of synapses between IHCs and the high threshold and low spontaneous rate population of primary afferent neurons [51]. EcochG is the best electrophysiological measure for either $\mathrm{OHC}$ or IHC and auditory nerve output. Persistent depression of the amplitudes of both CAP and SP in response to supra-threshold sounds is the prominent occurrence which happens in hidden hearing loss, which is representative of IHC-afferent synapse as well as hair cell malfunction [19].

\section{Perilymphatic fistula (PLF)}

Making a crossed incision on the round window membrane of guinea pig is a known way for modeling perilymphatic fistula. This procedure makes several changes in EcochG components, including SP and AP amplitude reduction and latency increase, and increases in the SP/AP ratios. The proposed mechanism for the changes which are observed by this intervention is related to attenuation in the afferent nerve fibers activity, as well as anatomic and functional chance in hair cells behavior, specially their active cochlear mechanism [18].

\section{Cochlear Ischemia}

An experimental local ischemia model of the guinea pig cochlea is reported frequently in literature. In this method, mechanically compressing anterior inferior cerebellar artery results in reduction of cochlear blood flow. The degree of induced cochlear ischemia is correlated with the alternations in N1 and N2 parameters of EcochG. As CAP of the cochlear nerve are sensitive to anoxia or ischemia, lower rate of cochlear blood flow is related to shorter survival time of $\mathrm{N} 1$ and $\mathrm{N} 2$ or prolongation of their latencies [17].

\section{Conclusion}

Guinea pigs are good animal models for human cochlea and they can help test different hypothesis, disease effects on cochlea, and treatments for diseases.

\section{References}

1. Melby EC, Altman NH (1974) Handbook of laboratory animal science. Volume 2. CRC Press Inc.

2. Hall JW (2007) New handbook of auditory evoked responses. Volume 1. ASHA.

3. Van Emst MG, Klis SF, Smoorenburg GF (1996) 4-Aminopyridine effects on summating potentials in the guinea pig. Hearing research 102(1-2): 70-80.

4. Skinner LJ, Enée V, Beurg M, Jung HH, Ryan AF, et al. (2003) Contribution of $\mathrm{BK} \mathrm{Ca}^{+}$-activated $\mathrm{K}+$ channels to auditory neurotransmission in the Guinea pig cochlea. Journal of neurophysiology 90(1): 320-332.

5. Nouvian R, Ruel J, Wang J, Guitton MJ, Pujol R, et al. (2003) Degeneration of sensory outer hair cells following pharmacological blockade of cochlear KCNQ channels in the adult guinea pig. European Journal of Neuroscience 17(12): 2553-2562.

6. Zinn C, Maier H, Zenner H, Gummer AW (2000) Evidence for active, nonlinear, negative feedback in the vibration response of the apical region of the in-vivo guinea-pig cochlea. Hearing research 142(1-2): 159-183.

7. Gosepath K, Heinrich UR, Ecke U, Maurer J, Amedee R, et al. (2000) Possible roles of nitric oxide in the physiology and pathophysiology of the guinea pig cochlea. European archives of oto-rhino-laryngology 257(8): 418-424.

8. Marcon, S, Patuzzi R (2008) Changes in cochlear responses in guinea pig with changes in perilymphatic K+. Part I: summating potentials, compound action potentials and DPOAEs. Hearing research 237(1-2): 76-89.

9. Brown DJ, Chihara Y, Curthoys IS, Wang Y, Bos M (2013) Changes in cochlear function during acute endolymphatic hydrops development in guinea pigs. Hearing research 296: 96-106.

10. Smeds H, Eastwood HT, Hampson AJ, Sale P, Campbell LJ, et al. (2015) Endolymphatic hydrops is prevalent in the first weeks following cochlear implantation. Hearing research 327: 48-57.

11. Ozer F, Unal OF, Atas A, Tekin O, Sungur A, et al. (2008) Evaluation of the effect of dexamethasone in experimentally induced endolymphatic hydrops in guinea pigs. American journal of otolaryngology 29(2): 8893.

12. Brown D, Chihara Y, Wang Y (2013) Changes in utricular function during artificial endolymph injections in guinea pigs. Hearing research 304: 70-76.

13. Hai Bo Ye, Hai Bo Shi, Jian Wang, Da Lian Ding, Dong Zhen Yu, et al. (2012) Bilirubin induces auditory neuropathy in neonatal guinea pigs via auditory nerve fiber damage. Journal of neuroscience research 90(11): 2201-2213.

14. Hai Bo Ye, Jian Wang, Wei Tian Zhang, Hai Bo Shi, Shan Kai Yin (2013) Taurine attenuates bilirubin-induced neurotoxicity in the auditory 


\section{Global Journal of Otolaryngology}

system in neonatal guinea pigs. International journal of pediatric otorhinolaryngology 77(5): 647-654.

15. Fetoni AR, Ralli M, Sergi B, Parrilla C, Troiani D, et al. (2009) Protective effects of $\mathrm{N}$-acetylcysteine on noise-induced hearing loss in guinea pigs. Acta Otorhinolaryngologica Italica 29(2): 70-75.

16. Emmerich 0045, Richter F, Reinhold U, Linss V, Linss W (2000) Effects of industrial noise exposure on distortion product otoacoustic emissions (DPOAEs) and hair cell loss of the cochlea-long term experiments in awake guinea pigs. Hearing research 148(1-2): 9-17.

17. Kaoru Ogawa, Jin Kanzaki, Shigeo Ogawa, Nobuaki Tsuchihashi, Yasuhiro Inoue, etal. (1996) Electrocochleography during experimental cochlear ischemia of the guinea pig. Acta oto-laryngologica, 116(2): 253-256.

18. Onishi ET, Fukuda Y (2010) Perilymphatic fistula in guinea pigs: natural evolution versus surgical treatment. Brazilian journal of otorhinolaryngology 76(2): 178-184.

19. Mulders WHAM, Chin IL, Robertson D (2018) Persistent hair cell malfunction contributes to hidden hearing loss. Hearing research 361 45-51.

20. Stengs CH, Klis SF, Huizing EH, Smoorenburg GF (1998) Cisplatin ototoxicity. An electrophysiological dose-effect study in albino guinea pigs. Hearing research 124(1-2): 99-107.

21. Stengs CH, Klis SF, Huizing EH, Smoorenburg GF (1997) Cisplatininduced ototoxicity; electrophysiological evidence of spontaneous recovery in the albino guinea pig 1 . Hearing research 111(1-2): 103113.

22. Van Ruijven MW, De Groot JC, Klis SF, Smoorenburg GF (2005) The cochlear targets of cisplatin: an electrophysiological and morphological time-sequence study. Hearing research 205(1-2): 241-248.

23. Klis SF, O'Leary SJ, Hamers FP, De Groot JC, Smoorenburg GF (2000) Reversible cisplatin ototoxicity in the albino guinea pig. Neuroreport 11(3): 623-626.

24. Cardinaal RM, de Groot JC, Huizing EH, Veldman JE, Smoorenburg GF (2000) Cisplatin-induced ototoxicity: morphological evidence of spontaneous outer hair cell recovery in albino guinea pigs? Hearing research 144(1-2): 147-156.

25. Zheng J, Ren T, Parthasarathi A, Nuttall AL (2001) Quinine-induced alterations of electrically evoked otoacoustic emissions and cochlear potentials in guinea pigs. Hearing research 154(1-2): 124-134

26. Cappaert NL, Sjaak FL Klis, Hans Muijser, Beverly M Kulig, Luco C Ravensberg, et al., (2002) Differential susceptibility of rats and guinea pigs to the ototoxic effects of ethyl benzene. Neurotoxicology and Teratology 24(4): 503-510.

27. Lamm K, W Arnold (2000) The effect of blood flow promoting drugs on cochlear blood flow, perilymphatic $\mathrm{pO}(2)$ and auditory function in the normal and noise-damaged hypoxic and ischemic guinea pig inner ear Hearing research 141(1-2): 199-219.

28. Stronks HC, MC Aarts, and SF Klis (2010) Effects of isoflurane on auditory evoked potentials in the cochlea and brainstem of guinea pigs. Hearing research 260(1-2): 20-29.

29. Minoda R, Toriya T, Masuyama K, Yumoto E (2001) The effects of histamine and its antagonists on the cochlear microphonics and the compound action potential of the guinea pig. Auris Nasus Larynx 28(3): 219-222.

30. D’Aldin C, Puel JL, Leducq R, Crambes O, Eybalin M, et al. (1995) Effects of a dopaminergic agonist in the guinea pig cochlea. Hearing research 90(1-2): 202-211.

31. Juaristi JS, MS Martínez-Conde (2014) Latencia de los microfónicos cocleares. Acta otorrinolaringologica espanola 65(4): 231-236.
32. Bourien J, Tang Y, Batrel C, Huet A, Lenoir M, et al. (2014) Contribution of auditory nerve fibers to compound action potential of the auditory nerve. Journal of neurophysiology 112(5): 1025-1039.

33. Bergin M, Bird PA, Vlajkovic SM, Thorne PR (2015) High frequency bone conduction auditory evoked potentials in the guinea pig: Assessing cochlear injury after ossicular chain manipulation. Hearing research 330(A): 147-154.

34. Wuyts F, Van de Heyning PH, Van Spaendonck M, Van der Stappen A, D'Haese P, et al. (2001) Rate influences on tone burst summating potential amplitude in electrocochleography: clinicala and experimentalb data. Hearing research 152(1-2): 1-9.

35. Aran J (1979) Long-term recording of cochleo-neural potentials in the guinea pig, Chapt. 11. Auditory Investigation: The scientific and technological basis 233-261.

36. Johnstone J, Alder VA, Johnstone BM, Robertson D, Yates GK (1979) Cochlear action potential threshold and single unit thresholds. The Journal of the Acoustical Society of America 65(1): 254-257.

37. Versnel H, Agterberg MJ, de Groot JC, Smoorenburg GF, Klis SF (2007) Time course of cochlear electrophysiology and morphology after combined administration of kanamycin and furosemide. Hearing research 231(1-2): 1-12.

38. Van Emst MG, SF Klis, GF Smoorenburg (1995) Tetraethylammonium effects on cochlear potentials in the guinea pig. Hearing research $88(1-$ 2): 27-35.

39. McMahon CM, Patuzzi RB, Gibson WP, Sanli H (2008) Frequencyspecific electrocochleography indicates that presynaptic and postsynaptic mechanisms of auditory neuropathy exist. Ear and hearing 29(3): 314-325.

40. Brown DJ, RB Patuzzi (2010) Evidence that the compound action potential (CAP) from the auditory nerve is a stationary potential generated across dura mater. Hearing research 267(1-2): 12-26.

41. Sellick P, R Patuzzi, D Robertson (2003) Primary afferent and cochlear nucleus contributions to extracellular potentials during tone-bursts. Hear Res 176(1-2): 42-58.

42. Salt AN, SK Plontke (2010) Endolymphatic hydrops: pathophysiology and experimental models. Otolaryngol Clin North Am 43(5): 971-983.

43. Sirjani DB (2004) The influence of transducer operating point on distortion generation in the cochlea. J Acoust Soc Am 115(3): 12191229.

44. Valk WL, HP Wit, FW Albers (2004) Evaluation of cochlear function in an acute endolymphatic hydrops model in the guinea pig by measuring low-level DPOAEs. Hear Res 192(1-2): 47-56.

45. Valk W, H Wit, F Albers (2006) Rupture of Reissner's membrane during acute endolymphatic hydrops in the guinea pig: a model for Ménière's disease? Acta Otolaryngol 126(10): 1030-1035.

46. Flock Å, B Flock (2000) Hydrops in the cochlea can be induced by sound as well as by static pressure. Hear Res 150(1-2): 175-188.

47. Kakigi A, AN Salt, T Takeda (2010) Effect of artificial endolymph injection into the cochlear duct on perilymph potassium. ORL J Otorhinolaryngol Relat Spec 71(Suppl.1): 16-18.

48. Gao X, X Yang, B Zhang (2011) Neuroprotection of taurine against bilirubin-induced elevation of apoptosis and intracellular free calcium ion in vivo. Toxicol Mech Methods 21(5): 383-387.

49. Harding N, W Davies (1993) Cellular localisation of taurine in the organ of Corti. Hearing research 65(1-2): 211-215.

50. Liberman MC (2015) Hidden hearing loss. Scientific American 313(2): p. 48-53. 
51. Furman AC, SG Kujawa, MC Liberman (2013) Noise-induced cochlear neuropathy is selective for fibers with low spontaneous rates. J Neurophysiol 110(3): 577-586.

(C) BY $\begin{aligned} & \text { This work is licensed under Creative } \\ & \text { Commons Attribution 4.0 License } \\ & \text { DOI: } 10.19080 / \text { GJO.2018.15.555923 }\end{aligned}$

\section{Your next submission with Juniper Publishers} will reach you the below assets

- Quality Editorial service

- Swift Peer Review

- Reprints availability

- E-prints Service

- Manuscript Podcast for convenient understanding

- Global attainment for your research

- Manuscript accessibility in different formats

( Pdf, E-pub, Full Text, Audio)

- Unceasing customer service

Track the below URL for one-step submission https://juniperpublishers.com/online-submission.php 